\title{
Regulatory review of the environmental risk assessment of veterinary medicinal products in the European Union, with particular focus on the centralised authorisation procedure
}

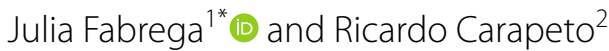

\begin{abstract}
In the EU, the requirement for a two-tier-based environmental risk assessment for a veterinary medicinal product applies for marketing authorisations submitted since 1993. This article outlines the framework for conducting environmental risk assessments and provides information about the outcomes and type of substances that often require a higher tier assessment due to environmental concerns, and the tools available within the relevant regulation to reassess potential risks from products already authorised (i.e., referral procedures (under Article 33(4), Article 35 of Directive 2001/82/EC and Article 30(3) of Regulation (EC) No 726/2004)). The majority of pharmaceutical veterinary medicinal products (>95\%) are considered to have a limited environmental release, and their risk assessment ends in the lowest tier (Phase I). To date, 19 referrals have been triggered as a result of environmental concerns, with the outcome from two out of the 19 concluding with an overall benefit/risk balance being negative, and resulting in the withdrawal of products from the market. The way environmental risk assessment for veterinary products will be addressed when the new veterinary regulation (Regulation (EU) 2019/6) comes into force on 28 January 2022 is also presented, and ongoing initiatives and published reports are discussed. The latter recommending policy actions to address water pollution by pharmaceutical residues and advocating a robust international cooperation and the establishment of a 'One Health' approach.
\end{abstract}

Keywords: Veterinary, Pharmaceuticals, Residues, Environment, Risk assessment, European Union, Regulation, Legislation

\section{Background}

In the European Union (EU), it was with the coming into force on 1 January 1995 of Council Regulation (EEC) No 2309/93 that a centralised community authorisation procedure for veterinary medicinal products was first established, enabling marketing authorisation holders to market a medicine and make it available throughout the EU based on a single marketing authorisation. Prior

\footnotetext{
*Correspondence: Julia.fabrega@gmail.com

${ }^{1}$ Veterinary Division, European Medicines Agency (EMA), Domenico

Scarlattilaan 6, 1083 HS Amsterdam, The Netherlands

Full list of author information is available at the end of the article
}

to 1995, veterinary medicinal products could only be authorised at national level, following recognised procedures for national authorisations. The aim of establishing a centralised EU system was to promote and strengthen the smooth functioning of the internal market in the pharmaceutical sector and to improve public and animal health by creating an EU-wide authorisation system based on the quality, safety and efficacy, with the exclusion of socio-economic considerations.

By the time the EU centralised authorisation procedure came into force in 1995, information on the environmental risks of veterinary medicinal products was already part of national marketing authorisation procedures, 
and their assessment was the responsibility of Member States. Submission of information on the environmental risks of a product became a requirement under Commission Directive 92/18/EEC (which came into force on 1 April 1993 and was later repealed by Directive 2001/82/ EC). Directive 92/18/EEC already required a two-phase tier-based environmental risk assessment, a framework which has been maintained and is still followed today (see Fig. 1). This basic framework provided by the abovementioned Directive was elaborated further by the EU Committee for Medicinal Products for Veterinary Use (CVMP) in 1997 [1], with the publication of a guidance document. This approach was later formalised and harmonised by the Veterinary International Conference on Harmonization (VICH), with the publication in 2000 and 2005 of two guidelines (GLs) for Phase I and Phase II, VICH GL6 [2] and GL38 [3], respectively (Fig. 1).

The need for an environmental risk assessment was included as a safety requirement for marketing authorisation applications, with any environmental risk arising from use of the product to be addressed within the marketing authorisation procedure. In practice, if a risk is identified, the first approach for risk control is incorporation of a precautionary measure (i.e., risk mitigation measures). For example, such a measure may consist of the following wording to be included in the product information of the veterinary medicinal product: 'Animals must remain stabled for ' $x$ ' days after treatment, until the concentration of < active substance $>$ in excreta is low enough to avoid adverse effects on dung fauna and their predators' [4]. If, with mitigation or management measures the risk cannot be controlled, then the environmental impact from use of a veterinary medicinal product has to be factored into the overall benefit-risk balance of the product. The consequence of this is that an environmental risk that cannot be controlled with appropriate mitigation or management measures, could lead to refusal of the authorisation of the veterinary medicinal product if this environmental risk is deemed to outweigh the overall product benefits.

New EU rules for veterinary medicinal products were adopted in December 2018 (Regulation (EU) 2019/6 repealing Directive 2001/82/EC and amending the provisions of Regulation (EC) 726/2004). The

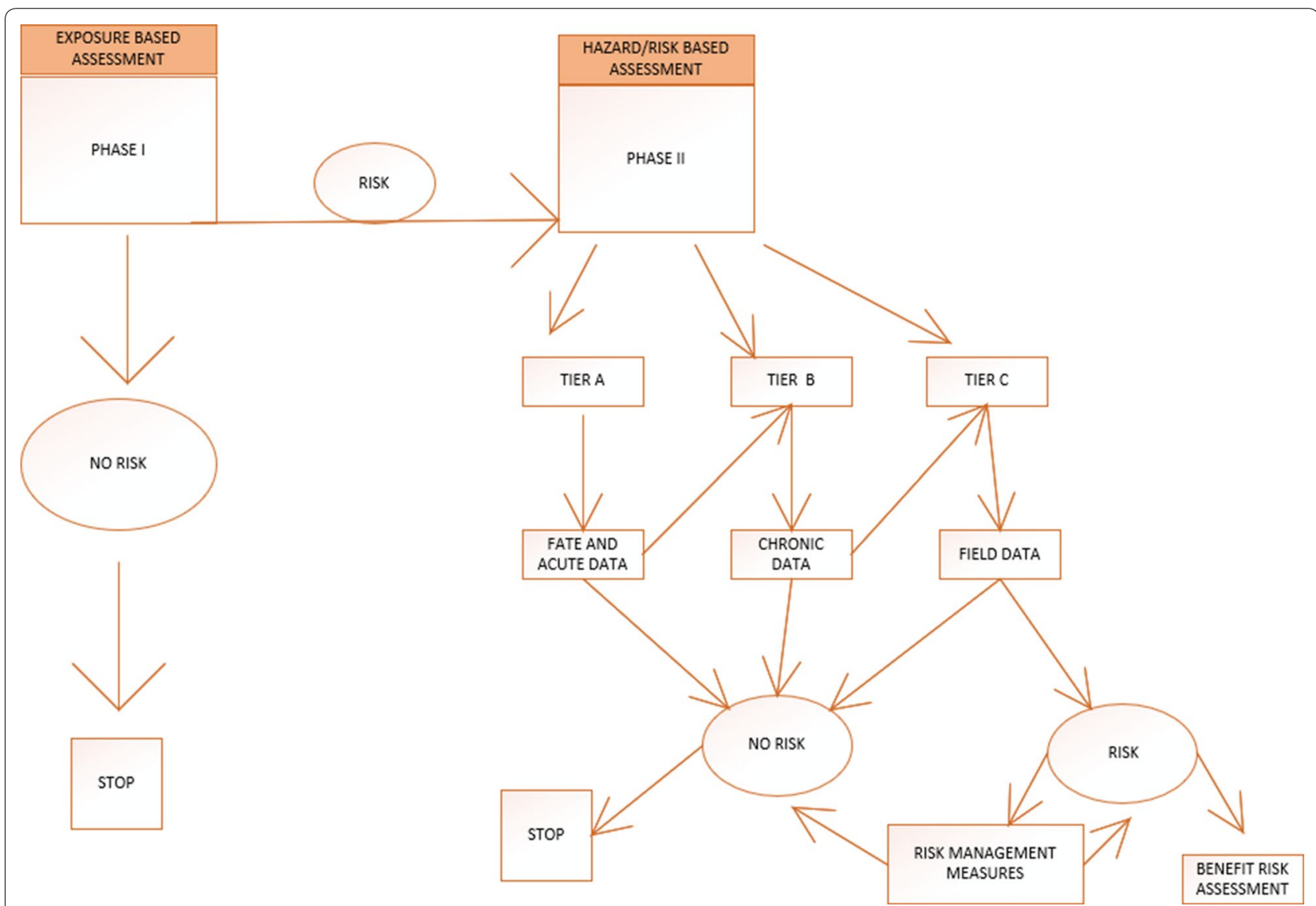

Fig. 1 Schematic representation of the framework for the environmental risk assessment for veterinary medicinal products in the EU 
new regulation will come into force on 28 January 2022, after the adoption of associated implementing rules. A number of recitals (i.e., the introductory paragraphs that provide context but are not themselves legally binding), in this new regulation, reflect the need for increased environmental protection. These recitals (1) advocate for the assurance of the highest level of environmental protection from authorised veterinary medicinal products (Recital 5), (2) acknowledge that, when a substance could pose a serious risk to the environment, monitoring requirements might need to be put in place in line with the Water Framework Directive (EU) 2010/75, including measures to reduce emissions from manufacturing (Recital 32, and 68), (3) recognise the impact from the overall environmental release from the same active substances used in different products, and suggest looking into alternatives to the current framework for risk assessments that could take this into account (Recital 35), as well as (4) call for the adequate reporting of environmental incidents and suspected adverse events observed following administration of veterinary medicinal products to animals (Recital 56). Further, the Regulation includes specific Articles (legally binding) that will have an impact on certain aspects of the framework for environmental risk assessments. These are covered in more detail in later sections of this publication, and include the assessment required for generic products, provisions on the authorisation of products containing persistent, bioaccumulative and toxic (PBT) substances, the need to potentially revise risk assessments for products authorised before 2005 (when VICH GL 38 came into force), and the possibility of more stringent environmental considerations for aquaculture products.

This review explains the framework for conducting environmental risk assessments in place in the EU since the early 1990s and provides information on the outcomes of the environmental risk assessments conducted during marketing authorisation procedures for centrally authorised products. It also reports on the use of this environmental risk assessment framework when applied to referral procedures (under Article 33(4), Article 35 of Directive 2001/82/EC and Article 30(3) of Regulation (EC) No 726/2004) when these referrals have been triggered due to environmental concerns. How the environmental risk assessment for veterinary medicinal products will be addressed after the new veterinary regulation [Regulation (EU) 2019/6] comes into force on 28 January 2022 is also presented, and ongoing initiatives and recently published reports are discussed, the latter recommending policy actions to address water pollution by pharmaceutical residues, and advocating a robust international cooperation and the establishment of a 'One Health' approach.

\section{Environmental risk assessments-the approach in place since 2005}

The environmental risk assessment for veterinary pharmaceutical products

Since 2005, in the EU, the assessment of environmental risks of veterinary pharmaceuticals has been done following the approach outlined in VICH guidelines 6 and 38. The risk assessment is tier-based and consists of two phases. The first phase, or Phase I (outlined in VICH guideline 6), is focused on determining the environmental exposure to the veterinary medicinal product, and concludes on whether or not a higher ecotoxicological assessment is needed, depending on the extent of environmental release as a result of the use of the product only (i.e., other product lifecycle stages such as manufacturing and disposal are excluded from exposure considerations). Currently, products that stop in Phase I are those considered to result in negligible environmental exposure (those products used for the treatment of individual animals/companion animals for example, or those for which predicted environmental concentrations do not exceed the threshold value of PECsoil $\geq 100 \mu \mathrm{g} / \mathrm{kg}$, as established in Phase I). The guideline indicates that for products with limited or negligible environmental exposure a more indepth assessment of the ecotoxicological effects is not warranted (i.e., 'no exposure $=$ no risk').

In limited cases, however, a Phase II assessment might be needed for any product that would otherwise stop in Phase I. The possibility to deviate from the straightforward application of the Phase I guideline is explained in the VICH GL 6, and is often referred to as the 'However clause.' When the 'However clause' is triggered for a product that does not initially meet the requirement of a Phase II assessment, the underlying concerns are related to its intrinsic properties, and potential impact on an environmental compartment of concern. When there is evidence that a risk to the environment cannot be ruled out, even when released in quantities resulting in environmental concentrations below those that would warrant by default a higher tier assessment, then a tailored risk assessment is carried out, targeted to specifically investigate the suspected environmental hazards of the product in the relevant environmental compartment/s. Examples of products that might fall into a 'However clause' triggered assessment might include products containing hormones, antibiotics, or those containing potential PBT substances.

If the conclusion of a Phase I environmental risk assessment is that environmental exposure is not low (e.g. PECsoil $\geq 100 \mu \mathrm{g} / \mathrm{kg}$ ), then a Phase II assessment (outlined 
in VICH guideline 38) has to be conducted. This phase is also tier based (with a tier A, tier B and tier C). Phase II-tier A focuses on generating hazard data in representative model organisms from different environmental compartments, usually soil and surface water, to calculate the highest concentration of the active pharmaceutical ingredient below which no adverse effects are expected (predicted no effect concentration, PNEC). Predicted environmental concentrations (PECs) are also calculated for the same compartments of concern assuming worst-case scenarios. When PECs for all environmental compartments are below the relevant PNECs, no further assessment is needed and the assessment can be concluded. Only when one or more PECs are above the PNECs in any specific compartment, the possibility for exposure and effect refinements is required, with the aim of generating further data on the environmental compartment of concern. Within the Phase II tier B assessment, the predicted environmental concentrations can be refined based on more realistic exposure estimates, and not only worst-case assumptions but additional and longer term effect studies can also be conducted for the refinement of the predicted no effect level values. If the conclusion, after conducting a Phase II tier B assessment, is that there is a risk from the use of the product from a particular compartment of concern, then field studies can be conducted for additional refinement based on a more realistic scenario (Tier $\mathrm{C}$ ), or risk mitigation measures are to be considered and included in the product information.
For veterinary medicinal products, any environmental risk must be considered in the overall benefit/risk assessment of the product, with the understanding that this could lead to refusal of its authorisation. This differs from the process in place for the authorisation of human medicines under EU law (Directive 2001/8/EC); for the latter environmental risks are not factored into the benefit/ risk balance of a product, so whilst an environmental risk assessment is undertaken for human medicinal products as well, it cannot result in a refusal to authorise.

In 2008, the CVMP developed an additional technical guidance in support of VICH GL6 and GL38 [5], with recommendations on how to calculate environmental exposure based on European farming practices, given that farming in different VICH regions varies, and as such environmental considerations regarding exposure are to be adapted accordingly. In addition, the CVMP has published a number of further guideline documents to support the assessment of the hazards and risks of veterinary medicinal products in the environment for specific types of substance (e.g. a guideline for the assessment of persistent, bioaccumulative and toxic (PBT) or very persistent and very bioaccumulative ( $\mathrm{vPvB})$ substances in veterinary medicinal products), or in particular compartments (e.g. a guideline on plant testing strategy in the risk assessment for veterinary medicinal products). These guidelines are published on the European Medicines Agency (EMA) website and are used by applicants for marketing authorisations when conducting their assessments.

Table 1 Outcome of environmental risk assessments (ERA) for centralised veterinary medicinal products (VMPs) since 1995

\begin{tabular}{|c|c|c|}
\hline & Number of VMPs ${ }^{a}$ & Reason for ending at phase I \\
\hline Total pharmaceutical VMPs & 108 & \\
\hline \multirow[t]{4}{*}{ Products with Phase I only (103 products) } & 16 & Treatment of individual animals \\
\hline & 3 & $\begin{array}{l}\text { Naturally occurring substance (such as electrolytes, peptides, proteins } \\
\text { and vitamins that do not alter the natural concentrations in the environ- } \\
\text { ment) }\end{array}$ \\
\hline & 15 & $\mathrm{PEC}<100 \mu \mathrm{g} / \mathrm{kg}$ \\
\hline & 69 & Use in companion animals only \\
\hline \multirow[t]{4}{*}{ Products with phase I and II (5 products) } & 1 & $\mathrm{PEC}>100 \mu \mathrm{g} / \mathrm{kg}$ \\
\hline & 2 & Potential PBT \\
\hline & 1 & High $\mathrm{PEC}_{\text {surface water }}$ and risk to dung fauna \\
\hline & 1 & Risk to plants \\
\hline Total immunological/biological VMPs & 101 & \\
\hline $\begin{array}{l}\text { Products with a higher tier environmental risk } \\
\text { assessment }\end{array}$ & 1 & Risk of vaccine spillage to wild population \\
\hline
\end{tabular}

a Data obtained from published European Public Assessment Reports (EPARs) for veterinary medicinal products (centrally) authorised by the European Medicines Agency, from October 2019 
Table 1 summarises the conclusions from environmental risk assessments performed in the frame of centralised marketing authorisation procedures in the $\mathrm{EU}$ (up to October 2019). Currently, there are a total of 209 centrally authorised veterinary medicinal products. For most pharmaceutical products (108 products), an environmental risk assessment has been conducted (in all 108 cases), with the majority (95\%) terminating after a Phase I assessment, whilst a Phase II assessment has been done for 5 products. In four cases (valnemulin for use in pigs, tylvalosin for use in pigs and fowl, pirlimycin for use in cattle and monepantel for use in sheep), a higher tier assessment was conducted due to the calculated predicted environmental concentration $\left(\mathrm{PEC}_{\text {soil }}\right.$, $\mathrm{PEC}_{\text {surfacewater, }}$ and $\mathrm{PEC}_{\text {dung }}$ ) exceeding recommended threshold values. For one case (product containing fluralaner for use in chicken), a straightforward application of the tier-based approach would have terminated the assessments in Phase I. However, a Phase II assessment was conducted by initiating the 'However clause' (VICH GL 6 provision explained above), and due to knowledge of the intrinsic properties of the substance (i.e. the potential PBT properties).

In 2018, the CVMP adopted, for first time, a negative opinion for a veterinary medicinal product intended for the treatment and prevention of parasitic infections in cattle [6], due to the long-term risks identified to cattle dung fauna which were considered by the Committee to outweigh the benefits of the product. This has been, thus far, the only new product (centrally authorised procedure), that has not been authorised in the EU due to environmental concerns. Yet, it is worth noting that the authorisations of two products were withdrawn due to their environmental risks (zinc oxide [7] and Pharmasin $100 \% \mathrm{w} / \mathrm{w}$ (tylosin [8]). Further information on the withdrawal of these products is given in the section detailing referral procedures.

\section{The environmental risk assessment for immunological products}

The environmental risk assessment for immunological products deviates from that of other pharmaceuticals. There are no internationally agreed guidelines on how an environmental risk assessment for immunologicals is to be conducted, but the CVMP developed in 1996, a guidance document to support the assessment of the risks of immunologicals before placing them in the market [9]. This document suggests that the nature of immunological veterinary medicinal products is such that, in the majority of cases, they will pose a very low environmental risk. Hence, the document does not recommend particular laboratory studies to be performed by applicants, but rather presents a framework consisting of the main elements to be addressed for quantifying a potential risk, these being (1) hazard identification (focused primarily on the potential for transmission and pathogenicity of live product organisms), (2) assessment of exposure to the hazard and likelihood that the hazard will occur, (3) assessment of the consequences of that exposure, (4) assessment of the level or risk (by consideration of the severity of any adverse consequences and the likelihood that they will occur), and (5) selection and assignment of appropriate control measures (risk management), as far as possible.

To date, the experience from environmental risk assessments for immunological veterinary medicinal products shows that such products generally tend not to pose a toxicological risk for the environment. For immunological products authorised centrally in the EU (101 products; Table 1), only vaccines with live components have been assessed regarding the likelihood of reverse spillover of vaccine strains from domesticated to wild populations of organisms. In only one instance (Table 1) was a higher tier risk assessment conducted. This was for a DNA vaccine intended to protect Atlantic salmon against salmon pancreas disease [10]. It is also important to note that, when genetically modified organisms' (GMO) components are used in veterinary vaccines, competent national authorities are also involved in the assessment of their environmental safety and a tailored environmental risk assessment is conducted in accordance with the requirements of the Directive 2001/18/EC.

\section{Environmental risk assessments-the approach in place from 1995 to 2005}

Whilst in the EU environmental risk assessments for centrally authorised veterinary medicinal products have been required for all new product authorisations since 1995, an internationally harmonised guideline on how to conduct a hazard and risk assessment for products with a significant environmental exposure (i.e. for a Phase II assessment) was not available in the EU until October 2005, when the VICH GL 38 was implemented. A Phase I environmental risk assessment guideline (VICH GL 6) was available since 2001, but this guideline addressed the likelihood of environmental exposure only. Prior to 2005, if the conclusion from a Phase I exposure assessment was that the use of a product would result in concentrations that exceed an agreed threshold [e.g. PECsoil and PECdung $>10 \mu \mathrm{g} / \mathrm{kg}$, PECgroundwater $>0.1 \mu \mathrm{g} / \mathrm{l}$ (see [1])], then the applicant had to further assess the hazards and characterise the risks as considered appropriate, and base the choice of studies to conduct on expert opinion, with no standardised and internationally agreed guidance available. Hence, VICH GL38 provided a muchneeded harmonised framework for guidance on the type 
of studies recommended when a higher tier assessment was required.

Recently, the lack of harmonised guidance on conduct of higher tier environmental risk assessments prior to 2005 has raised concerns amongst regulators, environment agencies and several stakeholders, who have questioned the soundness of environmental risk assessments conducted before that date. This uncertainty eventually led to the inclusion of a provision in the new veterinary regulation [Regulation (EU) 2019/6] that provides member states with the possibility to request additional environmental hazard and exposure data for products authorised prior to 1 October 2005, if considered necessary. The discussions on the reliability of environmental risk assessments before undertaken VICH GL38 were published and the need for a so-called 'catch up procedure' (i.e. aligning old environmental risk assessments with the latest guidelines) was also recommended by the European Commission in 2019, with the publication of the Commission strategic approach to the pollution of water by pharmaceutical substances [11].

There are concerns that a blanket review of pre-2005 products could lead to a significant administrative burden for marketing authorisation holders and regulators. It has been argued that, for products authorised before 2005 , generic products are likely to have been authorised after that year, and that full environmental risk assessments, in line with VICH GL 38, will have been undertaken for the generics. The accepted assumption for veterinary medicinal products is that the entry into the market of generic products does not lead to an increased environmental release of the product (this assumption is not applicable to exposure considerations for human pharmaceuticals [12]), as exposure assessments for veterinary medicinal products are conducted for local scenarios (e.g. farming field with pre-determined stocking density). Whether the animals are treated with the reference product or the generic product, the total predicted environmental release will not change. Based on this assumption, experts have argued that the environmental risk of the generic product is comparable to that of the reference product, and that consequently the existence of an environmental risk assessment for the generic product authorised after 2005 could override the need for an environmental risk assessment for the reference product. A counterargument has been that regulators have a natural tendency to seek consistency of outcomes in their assessments and that consequently, unless the potential environmental risks revealed in the assessment of a generic product were significant, there may have been limited appetite for raising concerns and thus arriving at conclusions that are inconsistent with those reached for the reference product. According to his view, the assumption, that comprehensive environmental risk assessments have been conducted for all products authorised prior to 2005 and for which a generic product was authorised after that date, could be questioned.

Only in situations when risks were identified during the assessment of the generic product, that questioned the validity of the risk assessment assigned to the reference product, and if there were unresolved disagreements between Member States in the validity of either assessment, this would then be resolved through referral procedures [under Article 33(4) and 35 of Directive 2001/82/ EC, and Article 30(3) of Regulation (EC) No 726/2004]. Further information on referral procedures is explained below.

Therefore, whilst in principle it could be reasonably assumed that an environmental risk assessment for a generic product will be the same as that of the reference product authorised prior to 2005, it has been noted as explained above that there is a tendency from regulators for consistency of assessments for generic and reference products, which might challenge this view. In addition, initial checks in national databases have come up with a number of products authorised prior to 2005 for which there have not been generics authorised.

\section{Referral procedures triggered as a result of environmental concerns}

Directive 2001/82/EC [to be repealed by Regulation (EU) 2019/6], and Regulation (EC) No 726/2004, foresees the possibility that potential risks to human, animal health and/or the environment not identified at the time of authorisation are re-assessed, post-authorisation (e.g. if there are concerns post-authorisation that leads to disagreements between Member States). Such risks are reassessed under so-called referral procedures. Referral procedures will consider new information and data made available since authorisation, with the aim of re-assessing the benefit-risk balance of the product(s) concerned, and consider the need for amendments to the marketing authorisation if necessary (e.g. changes of therapeutic dose, the target species, etc.).

To date, there have been 20 referrals triggered as a result of environmental concerns. The most common types of referral procedures used to address environmental concerns have been procedures under Article 33(4) and Article 35 of Directive 2001/82/EC, and Article 30(3) of Regulation (EC) No 726/2004. Referrals under Article 33(4) (14 referrals in total, requested by Member States, Table 2) have resulted from disagreements between Member States regarding the environmental risks posed by a generic product, often when the originator product had been authorised prior to 2005. Five referrals have been triggered under Article 35 (so-called class 


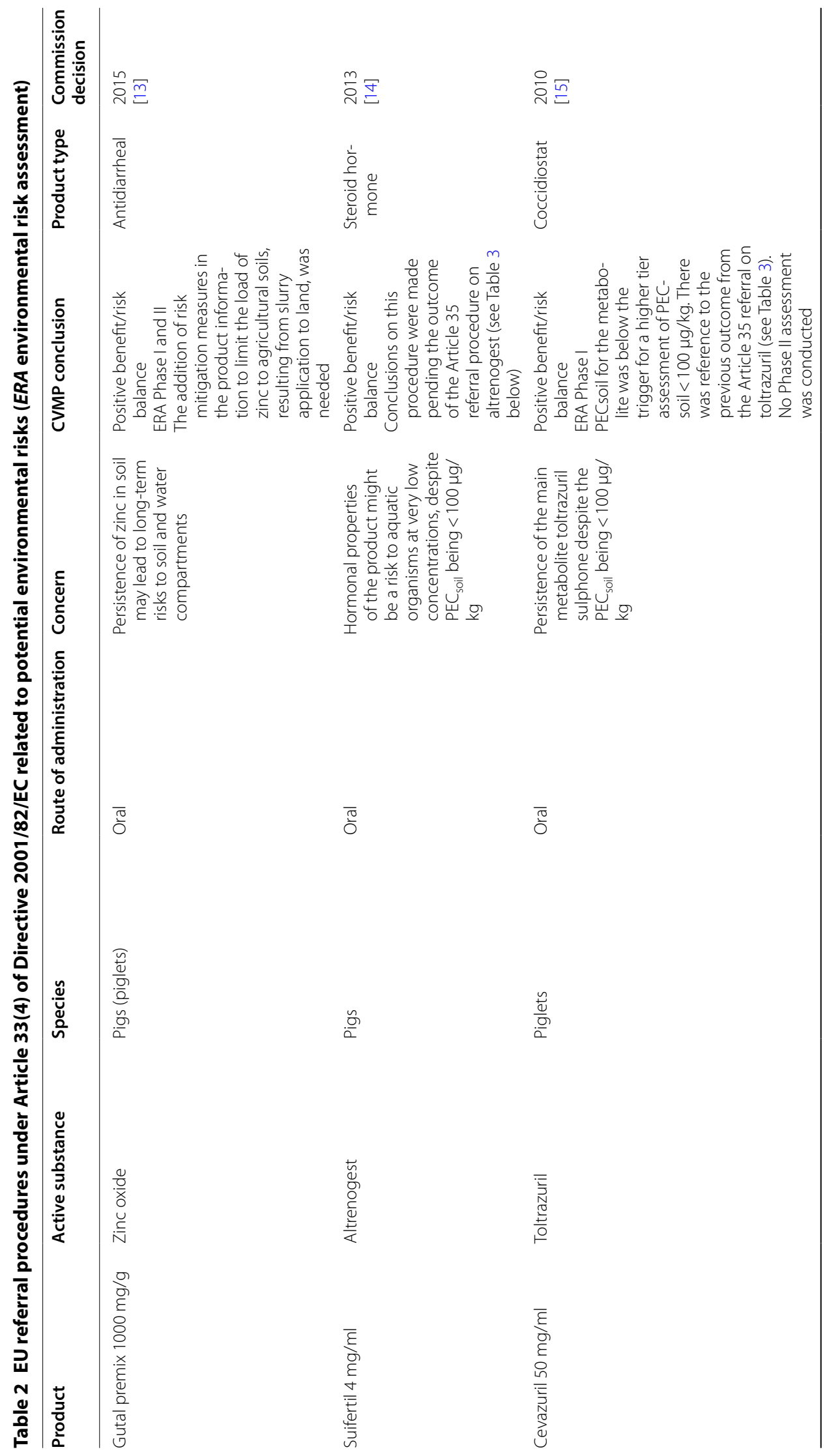




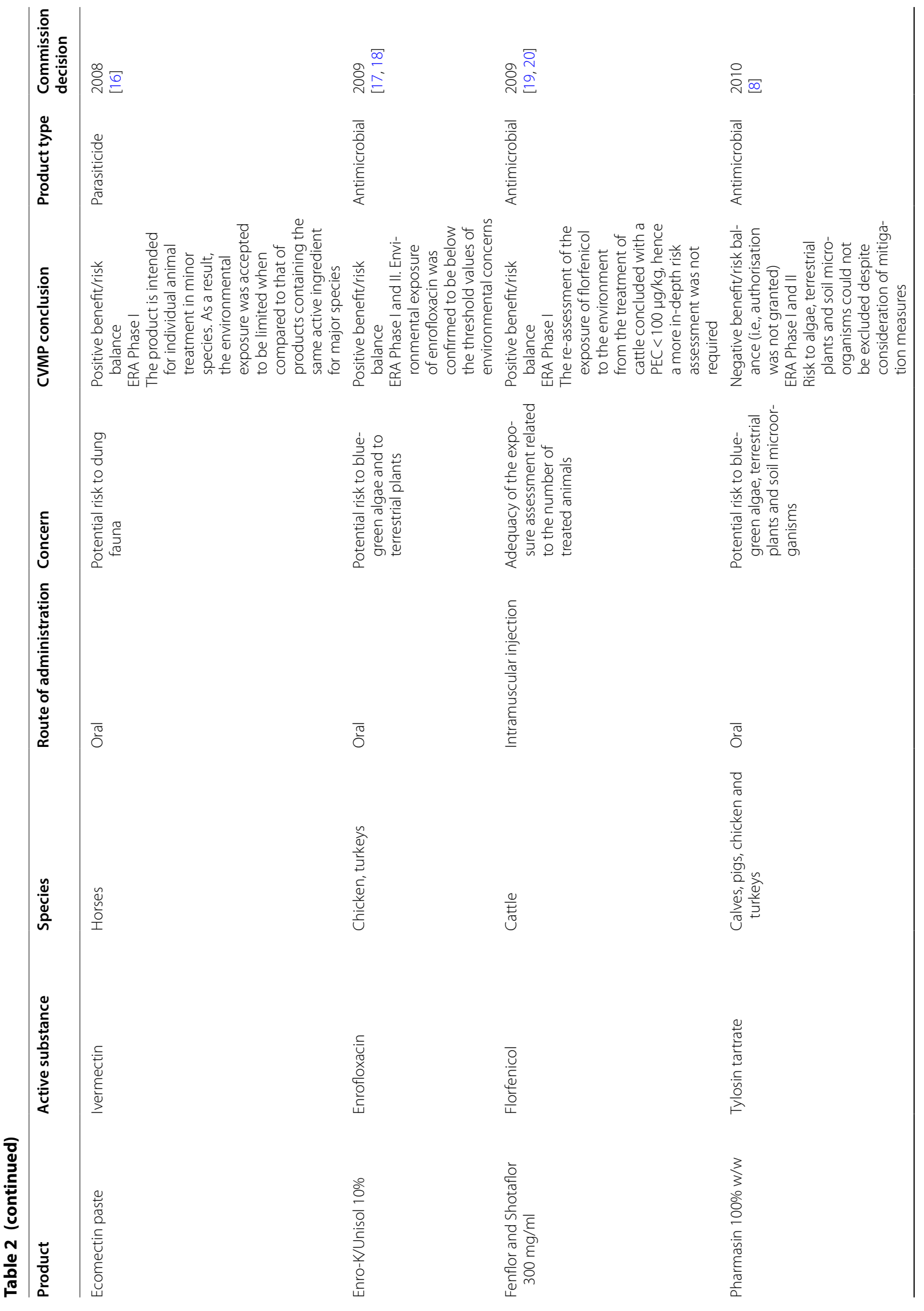




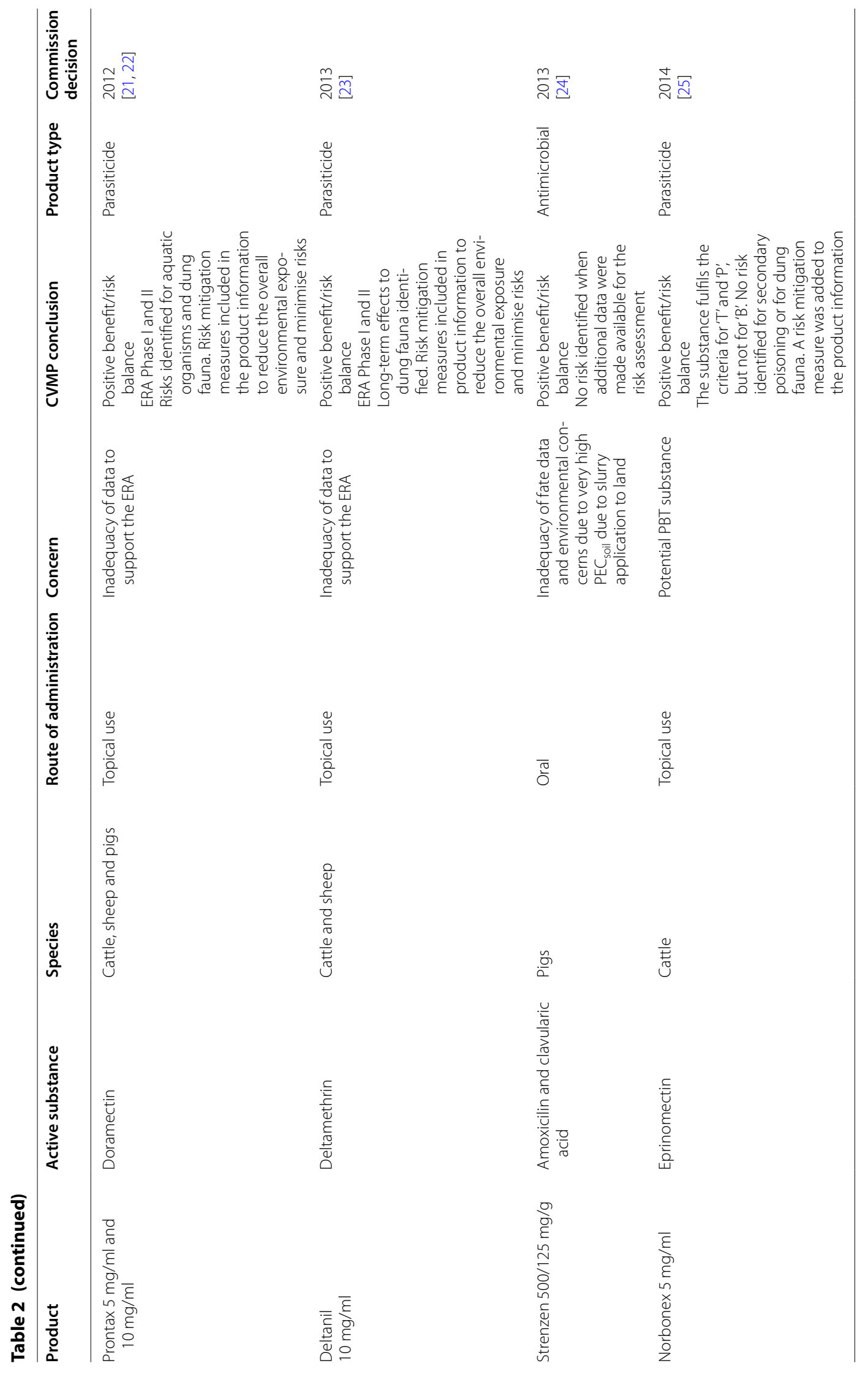




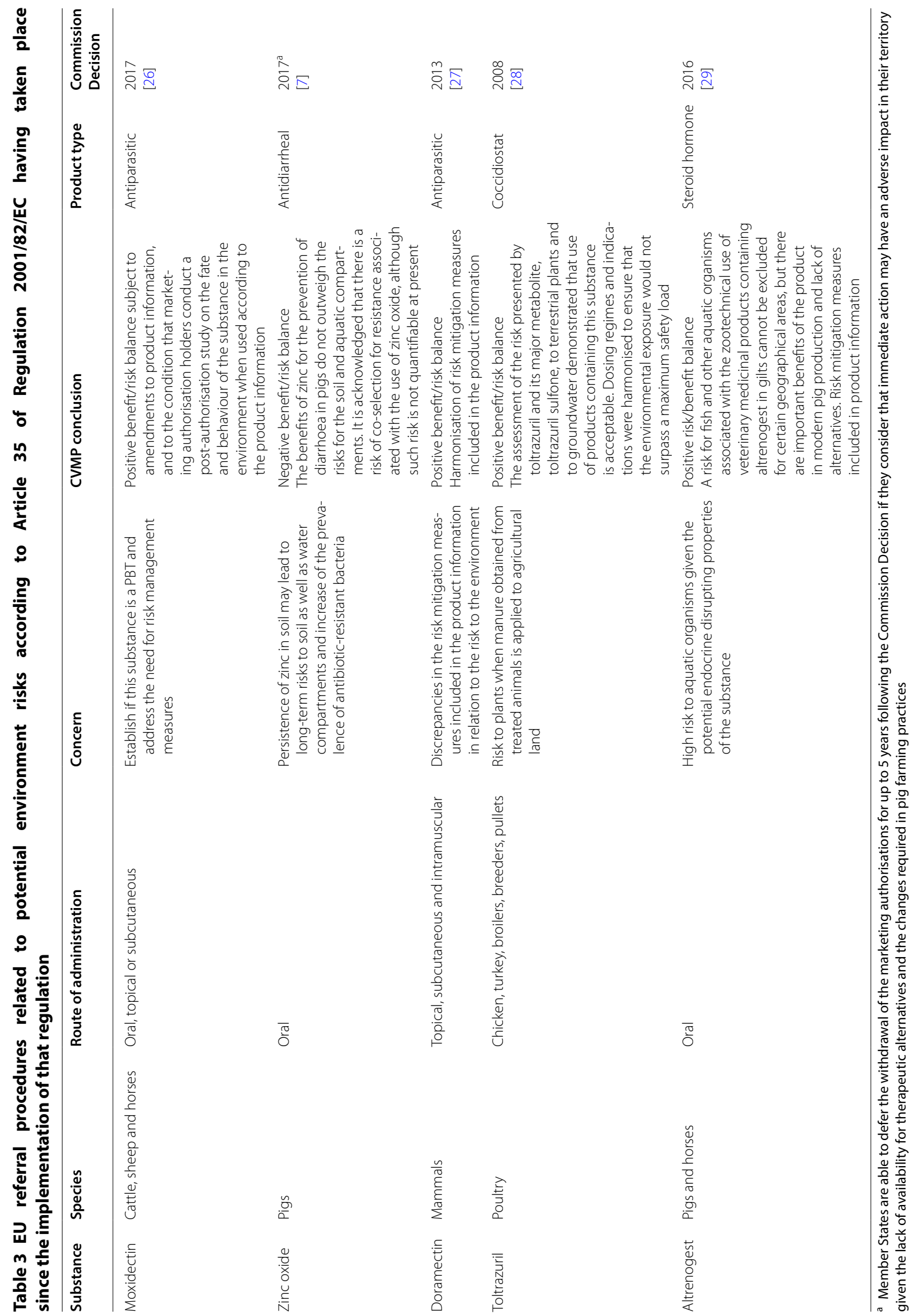




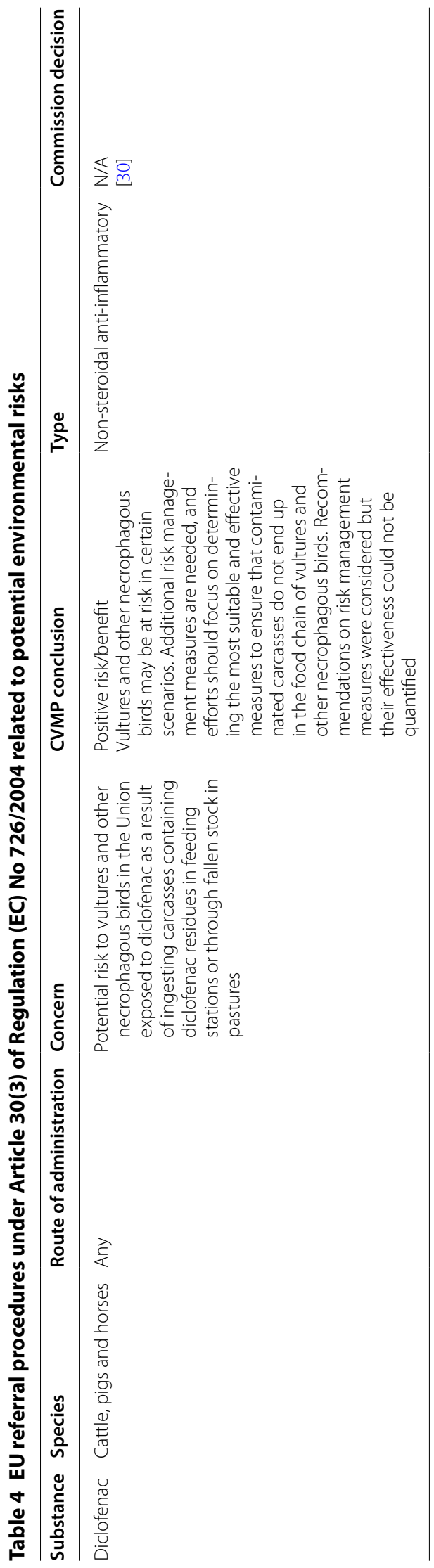


referrals involving several veterinary medicinal products and requested by Member States; Table 3), and one under Article 30(3) (requested by the European Commission, Table 4).

\section{EU initiatives and regulatory challenges}

The trend observed from recent initiatives recommending policy actions to address environmental pollution from pharmaceutical residues, is to call for a robust and global cooperation as done, for example, with antibiotic resistance initiatives and the so-called 'One Health' approach (aiming to tackle antimicrobial resistance with a multisectoral approach in mind) $[11,31]$.

In the EU, the potential contamination of soil and water from pharmaceutical residues has led to concern over potential environmental risks from exposure to very low levels of pharmaceuticals in surface water. This is reflected by the inclusion of Article $8 \mathrm{c}$ in the amended Priority Substances Directive in 2013 (2008/105/EC as amended by Directive 2013/39/EC), requiring the European Commission to propose a strategic approach to tackle the pollution of water by pharmaceutical substances. In March 2019, the Commission published its proposed Strategy in the form of a list of actions-mainly aimed at reducing environmental emissions-to be implemented by the relevant sectors in order to minimise water pollution through pharmaceuticals. The publication of this Strategy highlights the Commission's commitment to contribute to the EU reaching zero pollution levels by 2030 (The European Green Deal, [32]), whilst also maintaining medicine availability.

It is important to note, however, that whilst the implementation of many of these actions is feasible in the EU, other actions are seen as more challenging, particularly those related to the release of residues from manufacturing plants outside the Union. Indeed, Good Manufacturing Practices (GMP) and Best Available Techniques (BAT) are policy tools to prevent and control emission of industrial pollutants, and although GMP principles do not focus on environmental protection, there are suggestions and recommendations that environmental criteria should be added to the GMP framework, for instance effluent discharge limits and disclosure of pharmaceutical wastewater discharge from supply chains. A similar recommendation has been proposed by the Organisation for Economic Co-operation and Development (OECD) in its recent report on pharmaceutical residues in freshwater, recommending a number of policy measures to address and limit the environmental release of pharmaceutical residues across the pharmaceutical lifecycle [31]. An EU member state, Sweden, has already proposed that, within the EU GMP framework, measures to prevent the release of active ingredients from manufacturing plants should be incorporated in human and veterinary medicinal products' regulations [31]. Regarding veterinary medicinal products, the Commission Strategy for pharmaceuticals in the environment recommends three critical actions: (1) to develop guidance on the environmental risk assessment of medicinal products for use in aquaculture, (2) to assess the feasibility of setting up an EU-wide review system based on active pharmaceutical ingredients, rather than the current product-based risk assessment and (3) initiate a systematic catch-up procedure for veterinary medicinal products without an (adequate) environmental risk assessment (the latter discussed indepth above). Actions (2) and (3) are already captured in the new veterinary regulation and are described below, and the development of a guideline on risk assessment of aquaculture products (1) is viewed as a much needed by experts, particularly as methodologies for assessment of exposure to residues resulting from use of pharmaceuticals in aquaculture are not yet harmonised within the EU. In addition, given the yearly increase in production volume of this sector [33], and hence increasing demand for veterinary medicinal products for the treatment aquaculture species, together with provisions in the new veterinary regulation that can be viewed as trying to incentivise the development of such products, a comprehensive risk assessment guideline for these products is much needed.

As already mentioned, the new veterinary regulation, which comes into force on 28 January 2022 [Regulation (EU) 2019/6 repealing Directive 2001/82/EC and amending the provisions of Regulation (EC) No 726/2004], will bring in a number of changes. In this new regulation, the rules governing use of certain veterinary medicinal products in aquaculture systems have been revised. An aspect that has not changed in the new regulation from the Directive it replaces is the possibility to use a veterinary product authorised for species other than fish, to treat aquaculture fish species. However, whilst using a product developed for a terrestrial species on an aquatic species was previously accepted under certain circumstances and the responsibility of the veterinarian, the new veterinary regulation lays down more stringent conditions governing this practice. The regulation requires that a list of products that not only are authorised for terrestrial species but could also be used in aquatic species is developed within 5 years of the coming into force of the regulation (i.e. 22 January 2027), and when considering the inclusion of a product in this list, the risks to the environment from treating aquatic species should be taken into account.

In the new regulation, a remarkable recommendation and one that would change the paradigm for environmental risk assessments is the provision requiring the European Commission to assess the feasibility of shifting the assessment of environmental risks 
from a product-based approach to a substance-based approach (a recommendation also from EC Strategy on pharmaceuticals in the environment [11]). A substance-based risk assessment would be focused on developing comprehensive active substance monographs that can be referred to by applicants of new products or generics when preparing the product authorisation application. Whilst the initial implementation of this approach might be resource-demanding given the limited hazard and physicochemical data available for some active substances, in the long run, it would save resources for industry (as there would not be a need to replicate studies that already exist), as well as regulators, and would lead to harmonised and robust risk assessments providing a more comprehensive risk characterisation. According to the new regulation, the Commission has 3 years from the time the regulation comes into force (January 2022), to study the feasibility of setting up such a monograph system and submit its proposal to the European Parliament and the Council for review. The Commission may also consider other potential alternatives for environmental risk assessment, if the monograph approach is not deemed appropriate.

The new regulation also, for the first time, includes a legal provision allowing refusal of the authorisation of a product containing substances that meet the criteria for persistent, bioaccumulate and toxic (PBT) or very persistent and very bioaccumulative (vPvB), when the veterinary medicinal product is intended to be used in food-producing animals. The use of substances that are $\mathrm{PBT} / \mathrm{vPvB}$ is not specifically regulated under the current Directive, although efforts to mitigate environmental exposure from products containing such compounds have been addressed by the development of guideline documents by the CVMP [34, 35]. In contrast, the new veterinary regulation acknowledges the hazards associated with the use of these substances, and only in situations, where the use of a product containing a PBT substance is essential to prevent or control a serious risk to animal health, could granting of a marketing authorization be considered. Guidance on what constitutes a serious risk to animal health will be necessary and should be considered in the light of the WHO 'One Health' framework. It is important to bear in mind that this provision is only applicable for products to be used in food-producing species, whilst those products to be used in companion animals will not be affected. The reason for excluding PBT-containing products for use in companion animals from this provision might have been the assumption that environmental exposure to these products will be low or very low (as captured in VICH GL 6), although this assumption is being challenged by many [36].

\section{Conclusions}

Veterinary medicinal products can be authorised at EU level (centralised procedure), or at member state level (decentralised and mutual recognition procedure). Whilst the risk assessment framework is the same for any procedure followed, this article has focused on analysing the data from centrally authorised products only, as it was not possible to access data from products nationally authorised in individual member states. Available data show that, overall, the majority pharmaceutical veterinary medicinal products $(>95 \%)$ are considered to have a limited environmental release, and their risk assessment ends after a lowest tier evaluation (Phase I as outlined in VICH GL6).

Despite the assumption that, in most cases, contamination from veterinary residues is low, and hence products are exempt from higher tier environmental risk assessments that require specific data for the safety profile of the substances, environmental pollution caused by pharmaceutical substances is an emerging problem. Since the publication of the revised water framework Directive (2008/105/EC) in 2013, and the resulting legislative obligation for the European Commission to develop a strategic approach to reduce water pollution from pharmaceutical substances, efforts have been launched, at the European level, aimed at reducing overall emissions from products, harmonising and reducing efforts to generate hazard data and limiting the use of very hazardous substances in veterinary medicinal products (e.g. $\mathrm{PBT} / \mathrm{vPvB}$ substances). Proposals also call for a shift in the paradigm of current environmental hazard and risk assessments, for example with the recommendation to develop active substance-based assessments, moving away from product-based assessments. However, a number of stakeholders also consider that the actions do not go far enough, and that the need to broaden the scope of environmental risk assessments is justified based on existing knowledge (e.g. by only considering not only the risks arising from the use of the product but also conducting a more comprehensive assessment encompassing additional relevant scenarios such as that of veterinary active substance released from manufacturing plants). It is important to bear in mind that for other regulatory frameworks (e.g., EU chemicals, biocides and pesticides regulations), additional scenarios are already factored into the overall environmental risk assessment.

In the coming years, with the entry into force of the new veterinary regulation in January 2022 as well as with efforts driven by the European Commission to control the release of pharmaceutical into the 
environment, it is likely that the importance of addressing and reviewing the current approach towards environmental risks of pharmaceutical residues in the European Union will strengthen. For instance, this can already be seen in member states such as the Netherlands, that are taking national measures to improve their water quality by protecting drinking water from tonnes of pharmaceutical residues discharged into wastewater each year [37]. The potential impact of pharmaceutical residues on humans and wildlife is an issue of growing concern, as studies on concentrations of pharmaceuticals in surface waters as well as their effects in wildlife populations are increasingly reported in scientific publications. In addition, the environmental impact of pharmaceuticals is now reaching broader audiences through different means of communication and public media reporting. A similar effort to strengthen environmental efforts has been brought forward by the European Parliament in a non-binding political declaration [38], where, whilst supporting the Commission's strategic approach for pharmaceuticals in the environment, it notes the soft nature of some of the measures included in the strategy and proposes stronger additional suggestions for consideration by the Commission and Member States (e.g. addressing the manufacturing of pharmaceuticals).

In conclusion, the latest OECD and EC reports [11, 31], the EC strategy and new veterinary regulation indicate that there is a favourable climate for revisiting the current approach to the environmental risk assessment of veterinary medicines (e.g. exploring a substancebased assessment), and also for investigating expansion of the scope of its application (e.g. assessing the impact of emissions from production sites). The current discussions are the inevitable result of a regulatory framework embedded in a developing scientific environment, with the need to support the development of mitigation and management measures required to address potential pollution by veterinary residues.

\footnotetext{
Abbreviations

BAT: Best Available Techniques; CVMP: Committee for medicinal products for veterinary use; EC: European Commission; EMA: European Medicines Agency; ERA: Environmental risk assessment; EU: European Union; GMP: Good Manufacturing Practices; PBT/vPvB: Persistent, bioaccumulative and toxic/very persistent and very bioaccumulative; PEC: Predicted environmental concentration; PNEC: Predicted no effect concentration; VICH: Veterinary International Conference on Harmonisation; VMP: Veterinary medicinal product.

\section{Acknowledgements}

The authors would like to thank Ana Azaceta, Nick Jarrett, Michael T. Empl, Rhys Whomsley and Ruben Pita for their valuable comments and suggestions. Ricardo Carapeto-Chair of the Environmental Risk Assessment Working Party of the Committee for Medicinal Products for Veterinary Use.
}

\section{Disclaimer}

The views expressed in this article are the personal views of the authors and may not be understood or quoted as being made on behalf of or reflecting the position of the regulatory agency/agencies or organisations with which the authors are employed/affiliated.

\section{Authors' contributions}

JF wrote the manuscript and collated the data for Tables 1, 2, 3 and 4. RC contributed to "EU initiatives and regulatory challenges" and "Conclusions" sections of the manuscript. Both reviewed the final manuscript. Both authors read and approved the final manuscript.

\section{Funding}

Not applicable.

\section{Availability of data and materials}

Data have been obtained from European Public Assessment Reports (EPARs) for veterinary medicinal products published at the EMA website (http://www. ema.europa.eu) and from the Public Health—Union Register of medicinal products database, available online at https://ec.europa.eu/health/docum ents/community-register/html/index_en.htm.

\section{Ethics approval and consent to participate}

Not applicable.

\section{Consent for publication}

Not applicable.

\section{Competing interests}

The authors declare that they have no competing interests.

\author{
Author details \\ 1 Veterinary Division, European Medicines Agency (EMA), Domenico Scar- \\ lattilaan 6, 1083 HS Amsterdam, The Netherlands. ${ }^{2}$ Agencia Española de \\ Medicamentos y Productos Sanitarios (AEMPS), C/Campezo n 1, Edificio 8, \\ 28022 Madrid, Spain.
}

Received: 6 April 2020 Accepted: 28 June 2020

Published online: 20 July 2020

\section{References}

1. EMA (1997) Environmental risk assessment for veterinary medicinal products other than GMO-containing and immunological products (EMEA/ CVMP/055/96-Final). European Medicines Agency, London

2. EMA (2000) Guideline on environmental impact assessment for veterinary medicinal products phase I (CVMP/NCH/592/1998). European Medicines Agency, London

3. EMA (2005) Guideline on environmental impact assessment for veterinary medicinal products phase II (CVMP/NICH/790/2003). European Medicines Agency, London

4. EMA (2012) Reflection paper on risk mitigation measures related to the environmental risk assessment of veterinary medicinal products (EMA) CVMP/ERAWP/409328/2010). European Medicines Agency, London

5. EMA (2008) Environmental impact assessment for veterinary medicinal products in support of the VICH guidelines GL6 and GL38 (EMEA/CVMP/ ERA/418282/2005 Rev. 1 Corr.). European Medicines Agency, London

6. EMA (2018) European public assessment report for Longrange (EMEA/ V/C/004291/0000). European Medicines Agency, London

7. EC (2017) Commission implementing decision concerning, in the framework of Article 35 of Directive 2001/82/EC of the European Parliament and of the Council, the marketing authorisations for veterinary medicinal products containing "zinc oxide" to be administered orally to food producing species-Annex I-III. European Commission Brussels

8. EC (2010) Commission decision concerning, in the framework of Article 33 of Directive 2001/82/EC of the European Parliament and of the Council, the veterinary medicinal products "Pharmasin 100\% W/W Water Soluble Granules and associated names" which contain the active substance "Tylosine (tartrate)"—Annex I-III. European Commission, Brussels 
9. EMA (1996) Note for Guidance: Environmental risk assessment for immunological veterinary medicinal products (EMEA/CVMP/074/95). European Medicines Agency, London

10. EMA (2016) European public assessment report for Clynav (EMEA/ V/C/002390/0000). European Medicines Agency, London

11. EC (2019) European Union strategic approach for pharmaceuticals in the environment. European Commission, Brussels

12. Glowicka E, Lorincz S, Pesaresi E, Romero L, Verouden V (2009) Generic entry in prescription medicine in the EU: main charactersitics, determinants and effects. European Commission, Brussels

13. EC (2015) Commission implementing decision concerning, in the framework of Article 33 of Directive 2001/82/EC of the European Parliament and of the Council, the marketing authorisation for veterinary medicinal product "Gutal $1000 \mathrm{~g} / \mathrm{kg}$ premix for medicated feeding stuff for piglets", which contains the active substance "Zinc oxide"-Annex I-III. European Commission Brussels

14. EC (2013) Commission implementing decision concerning, in the framework of Article 33 of Directive 2001/82/EC of the European Parliament and of the Council, the marketing authorisations for veterinary medicinal product "Suifertil $4 \mathrm{mg} / \mathrm{ml}$ Oral Solution for Pigs and associated names", which contain the active substance "Altrenogest" European Commission, Brussels

15. EC (2010) Commission decision concerning, in the framework of Article 33 of Directive 2001/82/EC of the European Parliament and of the Council, the marketing authorisation for a veterinary medicinal product "CEVAZURIL $50 \mathrm{mg} / \mathrm{ml}$ oral suspension for piglets", which contains the active substance "Toltrazuril"-Annex I-III. European Commission, Brussels

16. EC (2008) Commission decision concerning, in the framework of Article 33 of Directive 2001/82/EC of the European Parliament and of the Council, the placing on the market of a veterinary medicinal product/products containing the active substance'Ivermectin'-Annex I-III. European Commission, Brussels

17. EC (2009) Commission decision concerning, in the framework of Article 33 of Directive 2001/82/EC of the European Parliament and of the Council, the placing on the market of a veterinary medicinal product "Enro-K 10\% Oral Solution"-Annex I-III. European Commission, Brussels

18. EC (2009) Commission decision concerning, in the framework of Article 33 of Directive 2001/82/EC of the European Parliament and of the Council, the placing on the market of a veterinary medicinal product "Unisol 10\% Oral Solution"-Annex I-III. European Commission, Brussels

19. EC (2009) Commission decision concerning, in the framework of Article 33 of Directive 2001/82/EC of the European Parliament and of the Council, the marketing authorisation for "Fenflor $300 \mathrm{mg} / \mathrm{ml}$ solution for injection for cattle", a veterinary medicinal product containing the active substance "Florfenicol". European Commission, Brussels

20. EC (2009) Commission decision concerning, in the framework of Article 33 of Directive 2001/82/EC of the European Parliament and of the Council, the marketing authorisation for "Shotaflor $300 \mathrm{mg} / \mathrm{ml}$ solution for injection for cattle", a veterinary medicinal product containing the active substance "Florfenicol"-Annex I-III. European Commission.

21. EC (2012) Commission implementing decision concerning, in the framework of Article 33 of Directive 2001/82/EC of the European Parliament and of the Council, the marketing authorisation for veterinary medicinal products "Prontax $5 \mathrm{mg} / \mathrm{ml}$ pour-on solution for cattle and associated names", which contain the active substance "Doramectin"—Annex I-III. European Commission, Brussels

22. EC (2012) Commission implementing decision concerning, in the framework of Article 33 of Directive 2001/82/EC of the European Parliament and of the Council, the marketing authorisation for veterinary medicinal products "Prontax $10 \mathrm{mg} / \mathrm{ml}$ solution for injection for cattle, sheep and pigs and associated names", which contain the active substance "Doramectin"—Annex I-III. European Commission, Brussels

23. EC (2013) Commission Implementing Decision concerning, in the framework of Article 33 of Directive 2001/82/EC of the European Parliament and of the Council, the marketing authorisations for veterinary medicinal product "Deltanil $10 \mathrm{mg} / \mathrm{ml}$ Pour-on Solution for cattle and sheep and Deltanil 100 mg Spot-on Solution for cattle", which contain the active substance "Deltamethrin"-Annex I-III. European Commission, Brussels
24. EC (2013) Commission implementing decision concerning, in the framework of Article 33 of Directive 2001/82/EC of the European Parliament and of the Council, the marketing authorisations for veterinary medicinal product "STRENZEN 500/125 mg/g powder for use in drinking water for pigs and associated names", which contain the active substance "Amoxicillin, clavulanic acid"-Annex I-III. European Commission, Brussels

25. EC (2014) Commission implementing decision concerning, in the framework of Article 33 of Directive 2001/82/EC of the European Parliament and of the Council, the marketing authorisation for veterinary medicinal product "Norbonex $5 \mathrm{mg} / \mathrm{ml}$ Pour-On Solution for Beef and Dairy Cattle", which contains the active substance" Eprinomectin "-Annex I-III. European Commission, Brussels

26. EC (2017) Commission implementing decision concerning, in the framework of Article 35 of Directive 2001/82/EC of the European Parliament and of the Council, the marketing authorisations for veterinary medicinal products containing moxidectin to be administered orally, topically or subcutaneously to cattle, sheep and horses-Annex I-III. European Commission, Brussels

27. EC (2013) Commission implementing decision concerning, in the framework of Article 35 of Directive 2001/82/EC of the European Parliament and of the Council, the marketing authorisations for all injectable and pouron veterinary medicinal products containing doramectin that are intended for use in mammalian food producing species_-Annex I-III. European Commission, Brussels. doi:C(2013) 5842

28. EC (2008) Commission decision concerning, in the framework of Article 35 of Directive 2001/82/EC of the European Parliament and of the Council, the marketing authorisations for veterinary medicinal products which contain the active substance "toltrazuril"-Annex I-III. European Commission, Brussels

29. EC (2016) Commission implementing decision concerning, in the framework of Article 35 of Directive 2001/82/EC of the European Parliament and of the Council, the marketing authorisations for veterinary medicinal products containing "altrenogest to be administered orally to pigs and horses" - Annex I-III. European Commission Brussels

30. EMA (2014) CVMP assessment report under Article 30(3) of Regulation (EC) No 726/2004 on the risk to vultures and other necrophagous bird populations in the European Union in connection with the use of veterinary medicinal products containing the substance diclofenac. European Medicines Agency, London

31. OECD (2019) Pharmaceutical residues in freshwater: hazards and policy responses. OECD Studies on Water, OECD

32. EC (2019) The European green deal. European Commission, Brussels

33. Tacon A (2018) Global trends in aquaculture and compound aquafeed production. Aquacult Soc J 49:33-46

34. EMA (2015) Guideline on the assessment of persistent, bioaccumulative and toxic (PBT) or very persistent and very bioaccumulative (vPvB) substances in veterinary medicinal products. European Medicines Agency, London

35. EMA (2016) Authorisation of veterinary medicinal products containing (potential) persistent, bioaccumulative and toxic (PBT) or very persistent and very bioaccumulative (vPvB) substances. European Medicines Agency, London

36. Little C, Boxall A (2020) Environmental pollution from pet parasiticides. Veterinary record 186(3):97. https://doi.org/10.1136/vr.m110

37. Charuaud L, Jarde E, Jaffrezic A, Thomas M-F, Le Bot B (2019) Veterinary pharmaceutical residues from natural water to tap water: sales, occurrence and fate. J Hazard Mater 361:169-186. https://doi.org/10.1016/j. jhazmat.2018.08.075

38. European Parliament (2019) Draft motion for a resolution of 12 November 2019 (2019/2816(RSP) on the Strategic approach to pharmaceuticals in the environment. https://www.europarl.europa.eu/meetd ocs/2014_2019/plmrep/COMMITTEES/ENVI/RE/2019/12-02/1192540EN. pdf. Accessed 6 Apr 2020

\section{Publisher's Note}

Springer Nature remains neutral with regard to jurisdictional claims in published maps and institutional affiliations. 